\title{
CONCEPÇÃO PEDAGÓGICA E CURRICULAR PARA O ESPORTE NA BASE NACIONAL COMUM CURRICULAR
}

\author{
Telma Adriana Pacifico MARTINELI ${ }^{1}$ \\ Carolina de Moura VASCONCELOS ${ }^{2}$ \\ Eliane Maria de ALMEIDA ${ }^{3}$
}

\begin{abstract}
RESUMO: O estudo teve objetivo analisar a BNCC para o Ensino Fundamental, em seus aspectos pedagógicos e curriculares, com foco na Educação Física e na concepção e classificação do esporte. Tratou-se de um estudo bibliográfico e documental fundamentado em uma perspectiva histórica- crítica. No documento, a Educação Física é um componente curricular que permite a aprendizagem de práticas corporais: brincadeiras e jogos, ginásticas, dança, lutas, práticas corporais de aventura e esportes. Essa concepção fundamenta-se na Praxiologia Motriz, que estuda a lógica interna e externa dos jogos e esportes, a partir da cooperação, interação com o adversário, desempenho motor e objetivos táticos da ação, na tentativa de romper com a perspectiva positivista, busca-se na linguagem e no significado da ação motriz uma vertente social do esporte. Essa concepção pelo viés da motricidade, continua se perpetuando na Educação Física, repercutindo na BNCC e contrariando as críticas histórias.
\end{abstract}

PALAVRAS-CHAVE: Política Educacional, BNCC, Educação Física, Concepções.

ABSTRACT: This study aimed to review the BNCC for Elementary Education in its Pedagogical and Curricular aspects, while focusing on the Physical Education (PE) and on the conception and classification of the sport. This is a bibliographical and documentary study based on a historicalcritical perspective. In the document, the Physical Education is a curricular component that facilitates the learning of body practices: games, gymnastics, dancing, fights, adventure body practices and sports. Such conception is based on Motor Praxeology, which studies the inner and outer reasoning of games and sports, considering the cooperation, interaction with the opponent, motor development and tactic aims of the action. In the attempt of breaking a positivist perspective, search for a social strand of sports through language and the meaning of the motor action. This conception continues to be perpetuated in the PE, reverberating in the BNCC and going against historical criticism.

KEYWORDS: Educational policy; BNCC; Physical Education; Conceptions.

\section{INTRODUÇÃO}

Em resposta ao convite para a reflexão sobre políticas públicas e educação, neste artigo, nos dedicamos a tratar da Base Nacional Comum Curricular (BNCC) como tema central, na especificidade da Educação Física. A BNCC é um documento normativo que define o conjunto de aprendizagens essenciais a serem apreendidos pelos alunos ao longo das etapas da Educação Básica (BRASIL, 2018).

\footnotetext{
1 Professora Doutora na Universidade Estadual de Maringá. E-mail: telmamartineli@hotmail.com

2 Pós-graduanda no Programa de pós graduação em educação da Universidade Estadual de Maringá. E-mail: carolvasconcelos.uem@gmail.com

3 Graduada em educação física pela Universidade Estadual de Maringá. Pós-graduanda em educação física pelo Programa de Mestrado em educação física em rede. E-mail: elianemarialmeida@hotmail.com
} 


\section{$=\mathrm{T} R A M A=$}

O documento é objeto de análise e discussão na área educacional, desde sua proposição na Lei no 9.394/1996 (LDB) ${ }^{4}$; o processo de elaboração e publicação da primeira e da segunda versão contou com consulta pública. Foram realizados estudos e debates de forma aligeirada em instituições de Educação Básica e Superior federais, estaduais e locais, e em entidades representativas que se manifestaram criticamente acerca do documento. Entretanto, os resultados das discussões e as "sugestões" de formulação e reformulação ocorreram por meio de ferramenta colaborativa on line, considerados "processos frios de escuta" (ANPED, 2016), e não atendeu às sugestões, de maneira que permitisse obter avanços na reformulação das versões da Base (BITTENCOURT, 2017).

Esse processo se reproduziu, concomitantemente, na área da Educação Física. Instituições e entidades representativas docentes, discentes e pesquisadores vinculados a ela se inseriram nesse processo de discussões sobre a BNCC. A Revista Motrivivência publicou, no vol. 28, n. 48 do ano de 2016, uma edição voltada especificamente para a discussão das versões preliminares da Base, que teve a contribuição de pesquisadores da área de diferentes perspectivas. O editorial de abertura, de caráter crítico, intitulou-se: "A Base Nacional Comum Curricular da Educação Básica em tempos de neoconservadorismo e de "neoliberalismo que saiu do armário'; mas também de resistência: Fora Temer!!!" (SILVA; PIRES; PEREIRA; 2016).

$\mathrm{Na}$ edição supracitada foram publicados onze (11) artigos relacionados à BNCC. Esses trabalhos apresentaram-se a partir de diferentes pontos de vista, isto é, tanto em uma visão mais crítica, como os estudos de Martineli et al (2016), Moreira et al (2016) e Rodrigues (2016), quanto convergente com os pressupostos presentes no documento, tais como Neira e Junior (2016) e Boscatto, Impolcetto e Darido (2016), entre outros..

Ao estudarmos as pesquisas publicadas na Revista Motrivivência verificamos que alguns estudos apontam que a BNCC pode contribuir para a superação dos problemas pedagógicos e para a aprendizagem dos conhecimentos necessários para o exercício da cidadania de forma crítica, reflexiva e emancipada. Ressaltam a autonomia que o documento oferece à equipe gestora da escola na elaboração do currículo e o papel do Estado na implementação e manutenção dessa política educacional (NEIRA E JUNIOR, 2016; BOSCATTO, IMPOLCETTO e DARIDO, 2016).

Alguns pesquisadores teceram críticas à área da Educação Física na BNCC , no que se refere à inserção da educação física na área de linguagens. Contudo, nota-se que a discussão sobre essa inserção é incipiente e que essa alocação vem acontecendo em diferentes documentos educacionais, sob o argumento de que a educação física é uma forma de desenvolver as relações sociais e participativas (MOREIRA et al, 2016; MARTINELI et al, 2016; RUFINO E NETO 2016; RODRIGUES, 2016).

No que se refere aos conteúdos elencados no documento, observa-se a influência de diferentes perspectivas teóricas, sobretudo concepções oriundas da pedagogia do esporte, de estudos do lazer e da praxiologia motriz. Os estudos sobre suas especificidades, ou seja, as concepções relacionadas às práticas corporais como esporte, danças, ginásticas, lutas, e práticas de aventura ainda parecem pouco exploradas nas discussões científicas da versão mais recente do documento. A concepção de esporte fundamenta-se na Praxiologia da Ação Motriz, elaborada originalmente pelo teórico francês Pierre Parlebas (1934). Por isso, torna-se necessário perscrutar os fundamentos dessa concepção europeia, uma vez que tais raízes têm influência histórica na Educação Física brasileira; além disso, é importante verificar quais os

\footnotetext{
4 Na Lei de Diretrizes e Bases da Educação Nacional (LDB, 1996), a Base deve nortear os currículos dos sistemas e redes de ensino das Unidades Federativas, como também as propostas pedagógicas de todas as escolas públicas e privadas de Educação Infantil, Ensino Fundamental e Ensino Médio, em todo o Brasil.
} 


\section{$=$ TRAMA $=$}

autores que estudam a Praxiologia da Ação Motriz no Brasil e como e como a prática é referenciada na BNCC.

O estudo que apresentamos, neste manuscrito, portanto, resulta desse processo de pesquisas e objetiva analisar a BNCC para o Ensino Fundamental - área da Educação Física, no que tange aos seus aspectos pedagógicos e curriculares, com foco na unidade temática esporte e sua concepção, com o intuito de compreender seus fundamentos norteadores. Desse modo, acreditamos poder contribuir para a ampliação dos estudos e discussões da área.

O exame documental foi realizado segundo as orientações de Shiroma, Campos e Garcia (2005), bem como de Pimentel (2001), os quais buscam construir uma metodologia crítica para a análise de documentos, articulada com a política educacional. Seguindo estas orientações, procedemos da seguinte maneira: definimos o documento de referência, a BNCC; procedemos a leitura rigorosa do documento; extraímos os pontos centrais: estrutura e organização do documento, princípios norteadores, conceitos e definições, bem como pressupostos relativos à Educação Física.

Na especificidade do objeto de pesquisa, a Educação Física e o eixo temático esporte, nos detivemos pormenorizadamente em apreender os conceitos e concepções teóricometodológicas, objetivos de aprendizagem e a organização curricular subjacente. Registramos estes pontos em uma ficha de exame e leitura. Posteriormente, buscamos aprofundar o estudo do objeto identificando, a partir dos elementos apreendidos, os pressupostos teóricos da concepção de esporte e, em uma investigação na bibliografia científica da área, ampliar sua compreensão, a partir de referências originais e interpretações de autores brasileiros.

O referencial teórico-metodológico que fundamentou as análises é de perspectiva histórica e crítica, uma vez que pondera as categorias centrais extraídas do objeto para a análise, considerando seus nexos com a totalidade das relações sociais e suas contradições (PAULO-NETTO, 2011).

A síntese destes estudos é apresentada em três tópicos principais: 1) aspectos gerais da Educação Física na BNCC e suas especificidades: jogos e brincadeiras, ginástica, dança, lutas, práticas corporais de aventura e esportes; 2) pressupostos teóricos da concepção de esporte de Pierre Parlebas - Praxiologia Motriz, que fundamenta a BNCC; 3) estudos sobre esta teoria no Brasil, aproximações pedagógicas e relação com a BNCC, conforme exposto a seguir.

\section{AS ESPECIFICIDADES DA ÁREA DA EDUCAÇÃO FÍSICA NA BNCC}

Neste tópico, nos dedicamos a apresentar os aspectos gerais presentes na BNCC, no que se refere à Educação Física, que se situa na área das Linguagens, e buscamos apreender os objetivos e princípios norteadores, conceitos e definições, bem como seus pressupostos.

Na Base, a Educação Física é considerada um componente curricular que permite a aprendizagem de práticas corporais entendidas como possibilidades expressivas dos sujeitos, e inseridas no âmbito da cultura. Dessa forma, compreende-se que, nas aulas de Educação Física, as práticas corporais devem garantir que os alunos ampliem sua consciência e tornemse sujeitos autônomos para apropriarem-se e utilizar a cultura corporal de movimento para as finalidades humanas (BRASIL, 2018).

Nesse documento, as práticas corporais apresentam três (3) elementos em comum: movimento corporal, organização interna e produção cultural, consideradas aquelas que são realizadas fora das obrigações e sem caráter instrumental. Estas habilidades privilegiam dimensões do conhecimento. (BRASIL, 2018).

Além disso, a BNCC estabelece seis (6) unidades temáticas relativas às práticas corporais: brincadeiras e jogos, esportes, ginásticas, dança, lutas e práticas corporais de 


\section{$=$ TRAMA $=$}

aventura, de modo que cabe à Educação Física garantir que em cada uma dessas unidades sejam desenvolvidas competências específicas.

As competências a serem desenvolvidas na Educação Física relacionam-se aos aspectos históricos, ao processo de ensino-aprendizagem e de reflexão crítica, à identidade cultural, aos sentidos e significados das práticas corporais, e por fim, ao desenvolvimento da saúde e do lazer. Isto porque, articulam-se as competências específicas da área de Linguagens buscando garantir o seu desenvolvimento, levando em consideração a natureza vivencial, experiencial e subjetiva do conhecimento.

O conhecimento a ser apreendido de acordo com a BNCC (BRASIL, 2018) depende dá atenção às 8 dimensões do conhecimento mencionadas anteriormente, cuja relação com as competências permite apreciar e criar diferentes formas de manifestações da cultura corporal do movimento. Para atingir o objetivo de desenvolver cada uma dessas competências, foram organizados na BNCC os conteúdos da Educação Física nos anos iniciais e finais do ensino fundamental, levando em consideração as unidades temáticas, os objetivos do conhecimento e as habilidades, conforme demonstra-se no quadro a seguir:

Quadro1. Organização da Educação Física na Base Nacional Comum Curricular 2018

\begin{tabular}{|c|c|c|}
\hline Anos & Unidades Temáticas & Objetos do conhecimento \\
\hline \multirow[t]{4}{*}{$1^{\circ}$ e $2^{\circ}$} & Brincadeiras e Jogos & $\begin{array}{l}\text { Brincadeiras e jogos da cultura popular } \\
\text { presentes no contexto comunitário e } \\
\text { regional }\end{array}$ \\
\hline & Esportes & $\begin{array}{l}\text { Esportes de marca } \\
\text { Esportes de precisão }\end{array}$ \\
\hline & Ginásticas & Ginástica geral \\
\hline & Danças & $\begin{array}{l}\text { Danças do contexto comunitário e } \\
\text { regional }\end{array}$ \\
\hline \multirow[t]{5}{*}{$3^{\circ}$ ao $5^{\circ}$} & Brincadeiras e Jogos & $\begin{array}{l}\text { Brincadeiras e jogos populares do Brasil } \\
\text { e do mundo } \\
\text { Brincadeiras e jogos de matriz indígena e } \\
\text { africana }\end{array}$ \\
\hline & Esportes & $\begin{array}{l}\text { Esportes de campo e taco } \\
\text { Esportes de rede/parede } \\
\text { Esportes de invasão }\end{array}$ \\
\hline & Ginásticas & Ginástica geral \\
\hline & Danças & $\begin{array}{l}\text { Danças do Brasil e do mundo } \\
\text { Danças de matriz indígena e africana }\end{array}$ \\
\hline & Lutas & $\begin{array}{l}\text { Lutas do contexto comunitário e regional } \\
\text { Lutas de matriz indígena e africana }\end{array}$ \\
\hline \multirow[t]{6}{*}{$6^{\circ}$ e $7^{\circ}$} & Brincadeiras e Jogos & Jogos Eletrônicos \\
\hline & Esportes & $\begin{array}{l}\text { Esportes de marca } \\
\text { Esportes de precisão } \\
\text { Esportes de invasão } \\
\text { Esportes técnicos-combinatórios }\end{array}$ \\
\hline & Ginásticas & Ginástica de condicionamento físico \\
\hline & Danças & Danças Urbanas \\
\hline & Lutas & Lutas do Brasil \\
\hline & Práticas corporais de aventura & Práticas corporais de aventuras urbanas \\
\hline \multirow[t]{4}{*}{$8^{\circ}$ e $9^{\circ}$} & Esportes & $\begin{array}{l}\text { Esportes de rede/parede } \\
\text { Esporte de campo e taco } \\
\text { Esportes de invasão } \\
\text { Esportes de combate }\end{array}$ \\
\hline & Ginásticas & $\begin{array}{l}\text { Ginástica de condicionamento físico } \\
\text { Ginástica de conscientização corporal }\end{array}$ \\
\hline & Danças & Danças de salão \\
\hline & Lutas & Lutas do mundo \\
\hline
\end{tabular}




\section{$=\mathrm{TRAMA}=$}

Fonte: Produzido pelos autores, com base em Brasil (2018).

O quadro apresenta uma organização dos conteúdos da Educação Física no ensino fundamental, considerando as unidades temáticas. Estes conteúdos possuem influência de diferentes perspectivas teóricas e, além disso, não propõem possibilidades concretas de atuação da prática pedagógica, o que pode dificultar o trabalho docente (MOREIRA et al, 2016; MARTINELI et al, 2016).

No que diz respeito ao ensino dos esportes, no documento da BNCC, fica expresso que "[...] as práticas derivadas dos esportes mantêm, essencialmente, suas características formais de regulação das ações, mas adaptam as demais normas institucionais aos interesses dos participantes, às características do espaço, ao número de jogadores, ao material disponível etc." (BRASIL, 2018, p. 211). Portanto, essa unidade temática subsidia-se em um modelo de classificação baseado na lógica interna dos esportes, tais como: "[...] critérios de cooperação, interação com o adversário, desempenho motor e objetivos táticos da ação" (BRASIL, 2018, p. 213).

A classificação da unidade temática esportes é dividida em esportes: de marca, de precisão, de invasão e técnico combinatórios, de rede/parede, de campo e taco e de combate. A ausência de adversários consiste na diferença principal dos esportes de marca para os de combate. Já os esportes de combate representam as modalidades em que o oponente deve ser subjugado, por meio de combinações de ataque e defesa, que só é possível na presença de um adversário (BRASIL, 2018).

Nos esportes de rede/quadra dividida ou parede de rebote reúnem-se as modalidades que se caracterizam por arremessar, lançar ou rebater a bola em direções ou setores da quadra adversária; e os esportes de invasão ou territorial são as modalidades que comparam a capacidade de a equipe levar um objeto a uma meta ou setor da quadra adversária. $O$ documento, também, traz os esportes de campo e taco, que reúnem as modalidades esportivas cuja característica é rebater a bola lançada pelo adversário o mais longe possível para tentar percorrer a maior distância ou maior número de bases possíveis; Os esportes de precisão são caracterizados pelo arremesso ou lançamento de objetos, procurando acertar um alvo específico; E por fim, os esportes de cunho técnico-combinatório compreendem as modalidades que visam à qualidade da ação motora/ movimento de acordo com padrões técnicocombinatórios (BRASIL, 2018). No tópico a seguir, nos dedicamos a tratar desta concepção de esporte, como resultado do estudo que buscou identificar sua origem e seus fundamentos.

\section{FUNDAMENTOS DA PRAXIOLOGIA MOTRIZ}

Com base na caracterização, definição, dimensões e classificação dos esportes no eixo que trata do tema, buscamos na literatura científica elementos que nos permitissem identificar os pressupostos da concepção de esporte apresentada na BNCC. Este encaminhamento nos permitiu identificar que se tratava dos pressupostos da Praxiologia Motriz ou Ciência da Ação Motriz, desenvolvida por Pierre Parlebas. No Brasil, essa teoria é estudada e difundida desde 2000, e apresentada nos estudos de González (2004), Ribas (2005; 2014), Taborda (2014), , entre outros autores da área.

Parlebas nasceu em 1934 na França, foi professor do L'École Normale d'Éducation Physique (1965-1975) e do Institut Nationaldu Sport et de l'Éducation Physique (1975-1987). Tornou-se Doutor em ciências humanas e letras em Sorbonne e lecionou Ciências Sociais e Matemática, na Universidade Paris Descartes. Foi nomeado chefe de pesquisa do laboratório "Jogos Desportivos e Ciência da Ação Motriz". Em 1987, tornou-se professor de 


\section{$=$ TRAMA $=$}

Sociologia do Desporto na Universidade de Paris V (RENE, 1994). A influência de seus escritos atingiu países como Espanha e Brasil, o que lhe concedeu o título de doutor honoris. Além disso, atualmente permanece no campo educacional como presidente honorário do Centro de Treino de Métodos de Educação Ativa (CEMEA).

Em seus estudos sobre a ação motriz, Pierre Parlebas desenvolveu a Teoria da Praxiologia Motriz ou Ciência da Ação Motriz. Praxiologia relaciona-se à análise das causas produtoras e das normas que conduzem as ações humanas, e entende estas ações como todo comportamento propositado, aquele que busca atingir um dado fim, de longo alcance. Estuda, portanto, a conduta ou as regras de atuação.

Essa teoria fundamenta-se em Talcott Parsons (1902-1979), pois segundo Nora et. al (2016), o conceito de ação motriz, visto como um tipo de ação social constituinte das manifestações culturais, é uma teoria desenvolvida por esse autor. Talcott Parsons foi um sociólogo norte-americano ligado à teoria dos sistemas sociais e recebeu forte influência dos sociólogos franceses Durkheim e Weber. Para Parsons, a ação humana é motivada não pela racionalidade no sentido econômico, mas por mecanismos ligados a processos de aquisição de valores do indivíduo (NORA et. al, 2016). Parlebas "[...] apropriou-se deste conceito de ação social e desenvolveu o conceito de Ação Motriz como unidade de análise dos jogos e esportes", afirma Nora et al (2016, p. 1369).

Na sistematização da Praxiologia Motriz, Parlebas fundamentou-se também no linguista e filósofo Ferdinand de Saussure (1857-1913). O conceito da linguística estrutural desenvolvido por Saussure estuda as estruturas das diferentes formas de comunicação, estabelecendo uma forma de gramática. Parlebas apropriou-se deste conceito para criar um instrumento que permitisse a criação de um vocabulário científico para os jogos e os esportes (NORA, et al, 2016).

Ao considerar a Educação Física dentro dessa lógica estrutural da linguagem, Parlebas busca estudar todos os sistemas dos signos para que possa trazer a cientificidade aos jogos e aos esportes:

Este enfoque en la estructura de los sistemas de signos, que se denomina semiótica, es más amplio que la lingüística estructural porque abarca no sólo el lenguaje, sino también otros sistemas de signos y símbolos tales como las expresiones faciales, el lenguaje del cuerpo, los textos literarios y, de hecho, todas las formas de comunicación (CADAVI, p. 57, 2007).

A discussão quanto aos sistemas de signos mostra uma influência de Piaget (18961980), que ao elaborar a Epistemologia Genética discute sobre os sistemas de signos e sua função semiótica. Segundo Piaget (1983), a semiótica consiste nas representações de significados por meio da linguagem, imagem mental ou gestos. Lembrando que todo este processo de representações de significados ocorre respeitando cada um dos estágios de desenvolvimento estruturados por Piaget. A interação nesta perspectiva, apenas auxilia no desenvolvimento das estruturas mentais já existentes em cada um.

A inserção das discussões sobre as concepções linguísticas aplicadas às ações corporais pode ser vista também dentro de uma compreensão sistêmica abordada por Betti (1996), a qual discute sobre o processo de formação de conceitos científicos que permitam a compreensão do movimento humano e, ainda, estuda as possibilidades de aplicar as teorias semióticas ao ensino da Educação Física. (BETTI, 1996).

Nessa perspectiva, a Psicomotricidade é colocada em discussão no processo pedagógico da Educação Física. E este conceito é recuperado por Parlebas e reestruturado em uma perspectiva sociomotora. Em entrevista a Saraví, (2012), ele esclarece esta distinção ao afirmar que: "La psicomotricidad era realmente parcial y además estaba parcializada". Ao 


\section{$=$ TRAMA $=$}

contrário, "la psicosociologia es la ciencia de las interacciones, me dicuenta de que los psicomotricistas quieren a los individuos como sujetos aislados, de la misma forma que en el psicoanálisis" (SARAVÍ, p. 24, 2012). Parlebas explica, ainda, que:

Para vivir también es necesario que el niño conozca el mundo y se conozca a través de sus relaciones con el mundo. Ahí me dicuenta de que había que definir la psicomotricidad de outra manera diferente. Ya que hablamos de psicomotricidad, podemos utilizar también el término sociomotricidad, y darle una definición operacional: es psicomotor lo que no necessita ninguna interacción motriz conotros, y sociomotor lo que impone una comunicación, una interacción motriz con uno o vários otros. Es así como pude definir el campo psicomotor y el campo sociomotor, de forma operacional (SARAVÍ, p.24, 2012).

Evidencia-se aqui uma tentativa de superar este caráter de fragmentação e redução própria da psicomotricidade e complementá-la com uma perspectiva social, na qual a comunicação e a interação entre as pessoas e ações motoras permitem avançar para uma concepção sociomotora, com o propósito de agregar o social ao biológico, suplantando esta dicotomia. O social é expresso, por meio da comunicação, que não ocorre somente na fala entre pessoas, mas também nas ações motrizes que carregam sentido e significado. Por isso, Parlebas concebe essa teoria como ciência da ação motriz.

Desse modo, a Praxiologia Motriz ou Ciência da Ação Motriz está centrada no "[...] estudo da lógica interna dos jogos e esportes sem desconsiderar a lógica externa. A lógica interna é a estrutura lógica que constitui cada jogo e esporte, dos protagonistas e agentes ativos evolvidos e de suas regras" (NORA et. al, 2016). Esse estudo das lógicas internas responde à questão sobre o interesse pedagógico e da seleção dos métodos para o ensino.

Ao compreender a Educação Física como uma prática corporal em forma de codificação e significação social, a BNCC se aproxima da lógica estrutural de linguagem de Parlebas, pois, ao falar do movimento corporal, prioriza as experiências que os indivíduos têm e as significações que estes atribuem a estas experiências, em uma concepção sociomotora, em que o movimento corporal considera a organização interna, mas também o produto cultural.

Os conceitos da Praxiologia Motriz são identificados, também, em virtude de conceituar os esportes como práticas que são orientadas pela comparação de desempenhos entre indivíduos ou grupos e que são regidos por normas institucionalizadas. Esta mesma definição pode ser vista em Parlebas (1987) que define o esporte como "[...] l'ensemble fini et dénombrable des situations motrices codifiées sous forme de compétition et institutionnalisées" (PARLEBAS, 1987, p. 547).

Nesse sentido, ao ser questionado quanto à praxiologia motriz ser uma corrente da Educação Física, o próprio Parlebas é categórico ao afirmar que:

No, no es una corriente de la educación física, es una disciplina científica a la que uno puede dedicarse y que sirve de soporte para el desarrollo de una educación física válida y verificable. La praxiología motriz no puede ser una corriente de la educación física, ya que la educación física es una práctica, no una ciencia. [...] En la práctica, el professor crea, inventa, em función de los alumnos que tiene, del día... Por lo tanto la educación física no es una ciencia sino una práctica que se apoya al máximo em datos científicos (SARIVÍ, 2012, p. 26).

Isso pode explicar o fato de os estudiosos brasileiros da Educação Física buscarem aproximar a praxiologia motriz das concepções pedagógicas desta área do ensino, e o texto da BNCC se aproximar da abordagem Crítico-Emancipatória, como veremos a seguir. 


\section{$=$ TRAMA $=$}

\section{ESTUDOS SOBRE A PRAXIOLOGIA MOTRIZ NO BRASIL}

Em face do percurso metodológico adotado, dedicamo-nos a identificar os estudos desenvolvidos no Brasil sobre a obra de Parlebas, bem como sua repercussão na BNCC, em particular nos pressupostos apresentados no eixo temático esporte.

Constatamos que João Francisco Magno Ribas dedicou esforços nos estudos sobre praxiologia motriz no Brasil e tornou-se um dos principais divulgadores de seus pressupostos no país. Este pesquisador é líder do Grupo de Estudos Praxiológicos, GEP-Brasil, grupo que agrega pesquisadores sobre este tema no Brasil e Latino-América, em parceria com o Laboratório de Praxiologia Motriz do Instituto Nacional de Educação Física da Cataluña, Centro de Lleida, Espanha (DGP, 2018).

A criação do Grupo de Estudos Praxiológicos (GEP/Brasil) ocorreu em 2014, com o intuito de reunir pesquisadores brasileiros e estrangeiros nos estudos sobre a Praxiologia Motriz e promover seu reconhecimento acadêmico no continente latino-americano. Essa teoria já possui reconhecimento científico na Europa e esse grupo pretende consolidar as ações científicas dessa natureza, por meio da realização de eventos, atuação em projetos de ensino, pesquisa e extensão; realização de intercâmbios científicos, e produção intelectual conjunta entre os pesquisadores cadastrados, sob as seguintes linhas de pesquisas: Jogos Tradicionais, Esportes, Atividades Didáticas e Atividades Livres e Trabalho Pedagógico (DGP, 2018).

Ribas tem diversas produções sobre o tema e sua relação com a Educação Física. Em seu artigo intitulado: "Praxiologia Motriz: construção de um novo olhar dos jogos e esportes na escola", Ribas (2005, p. 113) explica que a teoria da Ação Motriz "consiste em um instrumento de compreensão do mundo dos jogos e esportes, essencialmente do estudo e compreensão da lógica interna". Para esse autor, na praxiologia motriz, a conduta motriz é uma forma de comportamento motor com significados e é o objeto próprio da Educação Física escolar (RIBAS, 2005). O esporte na BNCC fundamenta-se na Teoria da Ação Motriz, pois concebe o esporte de acordo com a lógica interna, com o objetivo de possibilitar a "distribuição das modalidades esportivas em categorias, privilegiando as ações motoras intrínsecas" (BNCC, 2018, p. 213).

No que se refere à transferência de estruturas e lógicas internas das atividades, Parlebas elaborou um sistema de classificação, o CAl, que "[...] é uma das grandes referências para caracterizar cada âmbito das atividades e possibilitar a transferência de estrutura" (RIBAS, 2005, p. 116). De acordo com a interpretação de Ribas (2005) para o contexto escolar, o CAl parte de dois critérios, um referente à forma de interação e o outro referente ao meio físico.

Ribas (2005) considera que a estrutura geral das atividades, tipos de interações, características essenciais, processos de tomadas de decisões, entre outros conceitos, irão auxiliar o professor no desenvolvimento do saber da Educação Física, tanto na dimensão do "saber fazer" quanto no "saber sobre o realizar corporal", em congruência com a "organização e seleção de conteúdos a partir do Sistema de Classificação (CAl) e das Grandes Situações Motrizes" (RIBAS, 2005, p.120). A BNCC, baseada nos critérios de Parlebas, classifica os esportes considerando a estrutura das atividades, a forma de interação e do meio físico. Portanto, divide esta prática em: esportes de marca, precisão, técnico-combinatório, rede/ quadra dividida ou parede de rebote, campo e taco, invasão ou territorial, e combate.

Os autores que se orientam por essa perspectiva afirmam que a Ciência da Ação Motriz não é uma abordagem da Educação Física ou uma metodologia de ensino, mas, sim, um conhecimento científico, referente à lógica de funcionamento de jogos e esportes, que produz novos conhecimentos sobre essas manifestações (NORA, et al., 2016).

Do mesmo modo, no artigo "Fundamentos metodológicos da pedagogia das condutas motoras como projeto pedagógico na Educação Física escolar" (SANTOS, SILVA e SANTOS, 2016), os autores buscam, a partir dos princípios epistemológicos, pedagógicos, teóricos e 


\section{$=$ TRAMA $=$}

metodológicos da praxiologia motriz, estabelecer os fundamentos dessa teoria para a aquisição de condutas motoras, por meio da lógica interna de cada esporte, com vistas a contribuir para a superação de práticas pedagógicas que se subsidiem na automatização de habilidades motoras das diferentes modalidades esportivas.

A partir desta compreensão, a BNCC reconhece que o ensino da Educação Física necessita de um caráter lúdico, que permita uma apreensão das lógicas internas de todas as manifestações e a troca entre os alunos e sociedade deste conhecimento adquirido. Por isto, delimitam-se as dimensões do conhecimento e as competências específicas a serem desenvolvidas nos alunos.

Chama-nos a atenção a tentativa de aproximação da Praxiologia Motriz ou da Teoria da Ação Motriz com concepções ou abordagens pedagógicas da Educação Física. Em seu trabalho de conclusão de curso de especialização, intitulado "Contribuições da praxiologia motriz para a abordagem crítico-superadora", e concomitantemente, no artigo Praxiologia motriz e a abordagem crítico-superadora: Aproximações preliminares", Araújo e Ribas (2014) elaboram, a partir dos pressupostos da praxiologia motriz e dos cinco passos metodológicos elaborados por Saviani, uma proposta para o ensino do voleibol. Os pesquisadores concluem que a utilização da praxiologia motriz pode contribuir para a formação dos alunos, a partir da compreensão da dinâmica interna dos jogos e esportes, para além da simples execução de gestos técnicos e de ensino baseado em modelos esportivizados; e, conscientes da realidade social.

Com esse mesmo intento, no artigo "Praxiologia motriz, trabalho pedagógico e didática na Educação Física", Nora et al., (2016) apresentou um estudo cujo objetivo foi sistematizar aproximações desta concepção à Pedagogia Histórico-Crítica, sob a perspectiva da abordagem Crítico-Superadora na Educação Física.

Ressaltamos que a concepção crítico-superadora é uma proposição pedagógica para organização escolar, sob a concepção metodológica do Materialismo Histórico, que na área da Educação Física propagou-se a partir do livro "Metodologia do ensino da Educação Física" produzido por um "coletivo de autores". (MELLO, 2014).

Os pressupostos da Pedagogia Histórico-Crítica não estão presentes, até onde estudamos, na BNCC, uma vez que os conteúdos são apresentados como práticas corporais e não como manifestações da cultura corporal. As elaborações de uma classificação destes conteúdos na perspectiva das habilidades motoras desenvolvidas não vão ao encontro de uma perspectiva crítica, que analisa cada um destes conteúdos de acordo com seu desenvolvimento histórico e sua relação com o trabalho humano. Por isto, à medida que a BNCC se aproxima da Praxiologia Motriz, distancia-se da Pedagogia Histórico-Crítica, por fundamentarem-se em pressupostos cujas matrizes teórico-filosóficas são distintas.

Por outro lado, em sua dissertação Taborda (2014) busca aproximar a praxiologia Motriz da concepção Crítico-Emancipatória da Educação Física; o autor conclui, com a sua investigação, que a praxiologia motriz pode instrumentalizar a ação pedagógica dos professores, bem como dialogar com a proposta de transformação didático-pedagógica do esporte, fundamentada em Eleonor Kunz, por meio da aproximação de elementos da didática comunicativa com elementos da lógica interna dos esportes.

Na BNCC, a Praxiologia Motriz está atrelada a uma forma de ensino pautada na concepção Crítico-Emancipatória, especialmente no conceito de "cultura corporal do movimento" e das ações comunicativas que envolvem o ensino do esporte (KUNZ, 1995). A BNCC considera que "as práticas corporais são textos culturais passíveis de leitura e produção" (BRASIL, 2018, p. 212) e que permitem aos alunos apreender significados culturais das 


\section{$=$ TRAMA $=$}

diferentes formas de culturas de movimento. O documento enfatiza a importância da ação comunicativa do esporte por ser a prática mais conhecida da contemporaneidade.

Salientamos que a concepção Crítico-Emancipatória tem como principal idealizador Eleonor Kunz, subsidiado em autores como Jürgen Habermas e Maurice Merleau-Ponty. O autor compreende que a Educação Física deve ter funções políticas e sociais e, baseada no diálogo, deve promover ao aluno a compreensão da realidade e torná-lo sujeito de sua própria ação. O principal conteúdo da Educação Física é a cultura corporal de movimento, delineada pelo esporte, danças e atividades lúdicas (KUNZ, 1995).

A cultura corporal de movimento é referenciada na BNCC ao discutir a vivência prática como produtora de significados, e demonstra a influência exercida pela concepção CríticoEmancipatória na determinação dos conteúdos a serem trabalhados, a partir da afirmação da importância dos indivíduos em aferirem significados as manifestações da cultura corporal de movimento.

Por meio da transformação didático-pedagógica do esporte e de críticas à racionalidade técnica, Kunz divide a aula de Educação Física em três momentos: trabalho, interação e linguagem (MELLO, 2014).

Nota-se que a utilização da teoria da ação motriz como propostas didáticas ou o emprego de metodologias de ensino com foco no ensino, a partir da lógica interna do jogo têm alguns adeptos no país, como pode-se observar no artigo de González (2004) "Sistema de classificação de esportes com base nos critérios: cooperação, interação com o adversário, ambiente, desempenho comparado e objetivos táticos da ação". Na BNCC, a presença desta concepção fica clara, ao analisar o modelo de classificação utilizado na estruturação dos esportes: Para a estruturação dessa unidade temática, "[...] é utilizado um modelo de classificação baseado na lógica interna, tendo como referência os critérios de cooperação, interação com o adversário, desempenho motor e objetivos táticos da ação" (BNCC, 2018, p. 213).

Com relação à aproximação dos fundamentos da praxiologia motriz com a proposta da transformação didático-pedagógica para o esporte, denominada Crítico-emancipatória, bem como a utilização da Praxiologia Motriz para a fundamentação de propostas curriculares, como sugere Nora et al (2016), observamos sua efetivação em propostas brasileiras, como a "Proposta Curricular do Rio Grande do Sul" (2009) e a Base Nacional Comum Curricular (BRASIL, 2018), conforme analisamos neste manuscrito.

É possível que devido ao fato da concepção Crítico-Emancipatória não se constituir como corrente pedagógica da Educação Física (PARLEBAS, citado por SARAVÍ, 2012), seja a razão do documento da BNCC buscar fundamentos metodológicos nesta concepção, mais dialógica e comunicativa, de crítica à racionalidade técnica-instrumental.

\section{CONSIDERAÇÕES FINAIS}

A área da educação e particularmente da Educação Física, na BNCC, especificidade do esporte, foco deste manuscrito, apresenta uma concepção da Ciência da Ação Motriz e a classificação dos esportes segundo esta concepção. Na tentativa de ruptura com uma perspectiva positivista, busca-se na linguagem e no significado da ação motriz uma vertente mais social no trato com esse tema. Essa concepção vem ganhando espaço nas políticas nacionais para a área da Educação Física, por conceber a ação motriz em uma perspectiva sistêmica, que dá significado ao movimentar-se humano. Tende a associar concepções com bases teóricas distintas e imiscíveis entre si, seja de cunho biologicista com de perspectiva 


\section{$=$ TRAMA $=$}

social, seja atrelando tais concepções às concepções críticas. Esta lógica parece se reproduzir na BNCC da especificidade da Educação Física, objeto particular aqui tratado.

O documento da Base mostra a predominância de uma vertente mais conservadora em termos pedagógicos para a área, talvez em virtude das representações científicas e políticas na Educação Física brasileira, especialmente da última década. Parece-nos necessário compreender melhor as concepções que norteiam a BNCC e especificamente para a área das linguagens, na qual se integra a Educação Física, na medida em que aponta para o aprendizado de conhecimentos e valores, por seguinte para a formação educacional de sujeitos com competências necessárias à sociedade vigente, no contexto complexo e contraditório, de retrocesso a políticas conservadoras no país. Os resultados da implantação dessas políticas, nos países, tem sido o empobrecimento pedagógico e a diminuição de avaliação formativa (RODRIGUES, 2016)

A Educação Física para o ensino fundamental proposta pela BNCC tem como aspectos pedagógicos as práticas corporais como um processo de apropriação de significações das ações motrizes e a importância na determinação de habilidades e competências a serem desenvolvidas, o que demonstra a influência da Praxiologia Motriz, elaborada originalmente por Pierre Parlebas. Os aspectos pedagógicos são fundamentados na concepção CríticoEmancipatória (KUNZ, 1995), considerando o conteúdo da educação física como as manifestações da cultura corporal de movimento. Essa concepção de estudos pelo viés da motricidade, reestruturada em uma perspectiva sistêmica, continua se perpetuando na área da Educação Física, repercutindo na BNCC, contrariando as críticas histórias a esta concepção.

\section{REFERÊNCIAS:}

ARAÚJO P. A., RIBAS, J. F. M. Contribuições da praxiologia motriz para a abordagem crítico-superadora. Disponível em: https://repositorio.ufsm.br/bitstream/handle/1/881/Araujo_Pablo_Aires.pdf?sequence=3. Acesso em: 20/03/2017.

BETTI, Mauro. Por uma Teoria da Prática. Motus Corporis. Rio de Janeiro, v. 3, n. 2, p. 73-127, dez. 1996. BITTENCOURT, J. A base nacional comum curricular: uma análise a partir do ciclo de políticas. In: XIII Congresso Nacional de Educação. Anais do EDUCERE. Paraná, 2017.

BRASIL. Base Nacional Comun Currícular. Ministerio da Educação. Brasília, DF, 2018. Disponivel em: http://basenacionalcomum.mec.gov.br/wp-content/uploads/2018/02/bncc-20dez-site.pdf. Acesso em: 07/08/2018.

KUNZ, E. Transformação didático-pedagógica do esporte. ljuí: Editora Unijuí, 1994.

MARTINELI, T. A. P.; MAGALHÃES, C. H.; MILESKI, K. G.; ALMEIDA, E. M.. A Educação Física na BNCC: concepções e fundamentos políticos e pedagógicos. Motrivivência. Santa Catarina, v. 28, n. 48, p. 76-95, setembro/2016. Disponível em: https://periodicos.ufsc.br/index.php/motrivivencia/article/view/21758042.2016v28n48p76/32564 Acesso em: 09/08/2018.

MELLO, R. A. A necessidade da Educação Física na escola. São Paulo: Instituto Lukács, 2014.

MOREIRA, L. R.et al. Apreciação da Base Nacional Comum Curricular e a Educação Física em foco. Motrivivência, v. 28, n. 48, p. 61-75, setembro/2016.

NEIRA, M. G.; JUNIOR, M. S. A Educação Física na BNCC: procedimentos, concepções e efeitos. Motrivivência. Santa Catarina, v. 28, n. 48, p. 188-206, setembro/2016. Disponível em: https://periodicos.ufsc.br/index.php/motrivivencia/article/view/45356 Acesso em: 09/08/2018.

NORA, D. D.; WALTER, J; BUFFON, E.; RIBAS, J. F. M. Praxiologia motriz, trabalho pedagógico e didática na educação física. Movimento, Porto Alegre, v. 22, n. 4, 1365-1378, out./dez. de 2016. Disponível em: $<$ http://seer.ufrgs.br/index.php/Movimento/article/view/65268>. Acesso em: 21/03/2018.

OLIVEIRA, G. T; RIBAS, J. F. M. Articulações da praxiologia motriz coma Concepção Crítico-Emancipatória. Movimento, Porto Alegre, v. 16, n. 01, p. 131-148, jan./mar. 2010. Disponível em: $<$ http://www.seer.ufrgs. br/Movimento/article/viewFile/9680/7521 >. Acesso em: 03/05/2018.

OLIVEIRA, A. A. B; PERIM, G. L. Fundamentos Pedagógicos do Programa Segundo Tempo. Maringá: EDUEM, 2009.

PARLEBAS, P. Eléments de sociologie du sport. Revue française de sociologie. França, n. 3, v. 28, p. 547550, 1987.

PAULO-NETTO, J. Introdução ao estudo do método de Marx. São Paulo: Editora Expressão Popular, 2011. PIAGET, J. A Epistemologia genética; Sabedoria e ilusões da filosofia. São Paulo: Abril Cultural, 1983. 


\section{$=\mathrm{TRAMA}=$}

PIMENTEL, A. O método da análise documental: seu uso numa pesquisa historiográfica. Cadernos de Pesquisa, n. 114, p. 179-195, novembro/ 2001. Disponível em: http://www.scielo.br/pdf/cp/n114/a08n114.pdf .Acesso em: 03/08/2018.

RENE, B. X. L'education physique Au XX e Siecleen France. Paris: Nouvelle, 1994.

RIBAS, J. F. M. Praxiologia Motriz: construção de um novo olhar dos jogos e esportes na escola. Motriz, Rio $\begin{array}{llllll}\text { Claro, } & \text { v.11 } & \text { n.2 } & \text { p.113-120, } & \text { mai./ago. } 2005 . & \text { Disponível }\end{array}$ http://www.rc.unesp.br/ib/efisica/motriz/11n2/10MRJ.pdf . Acesso em: 20/03/2017.

RIBAS, J. F. M. O voleibol e os novos olhares dos jogos esportivos coletivos. In: RIBAS, J. F. M (Org.). Praxiologia motriz e voleibol: elementos para o trabalho pedagógico. ljuí: Editora Unijuí, p. 21-56, 2014.

RODRIGUES, A. T. Base Nacional Comum Curricular para a área de linguagens e o componente curricular Educação Física. Motrivivência, v. 28, n. 48, p. 32-41, setembro/2016.

RUFINO, L. G. B; NETO, S. de S. Saberes docentes e formação de professores de Educação Física: análise da Base Nacional Comum Curricular (BNCC) na perspectiva da Profissionalização do Ensino. Motrivivência, v. 28, n. 48, p. 42-60, setembro/2016.

SARAVÍ, J. R. A praxiologia motriz: presente, passado e futuro. Entrevista com Pierre Parlebas. Movimento, Porto Alegre, v. 18, n. 01, p. 11-35, jan/mar de $2012 . \quad$ Disponível em: http://seer.ufrgs.br/Movimento/article/view/27065. Acesso em: Acesso em: 21/03/2018.

SILVA, M. R; PIRES, G. L.; PEREIRA, R. S. A Base Nacional Comum Curricular da Educação Básica em tempos de neoconservadorismo e de "neoliberalismo que saiu do armário"; mas também de tempos de resistência: Fora Temer!!!. Motrivivência. Santa Cataria, v. 28, n. 48, 2016. Disponível em: https://periodicos.ufsc.br/index.php/motrivivencia/article/view/2175-8042.2016v28n48p7/32530 Acesso em: 09/08/2018.

SHIROMA, E.O.; CAMPO, R. F.; GARCIA, R. M. C. Decifrar textos para compreender a política: subsídios teórico-metodológicos para análise de documentos. Perspectiva. Florianópolis, v. 23, n. 02, p. 427-446, jul./dez. 2005.

TABORDA, D. S. Aproximações teóricas entre a praxiologia motriz e a proposta transformação didáticopedagógica do esporte: por um diálogo da possibilidade. Dissertação (Mestrado). UFSM. Programa de PósGraduação em Educação Física. $\quad$ RS, $2014 . \quad$ Disponível em: http://repositorio.ufsm.br/bitstream/handle/1/6744/TABORDA\%2c\%20DOUGLAS\%20DOS\%20SANTOS.pdf? sequence=1\&isAllowed $=y$. Acesso em: 20/03/2017.

Recebido em 15-05-2018. Aceito em 14-08-2018. 